Gaos, J. Publicado en Revista Dianoia 1960, Año VI NUM. 6

\title{
CURSO DE ANTROPOLOGÍA
}

\section{ANTROPOLOGIA Y EUDEMONOLOGIA ${ }^{1}$}

La filosofía, esfuerzo por dar razón de cuanto existe, no precisamente por ser tal no debe esforzarse por dar razón de sí misma. Todo lo contrario. A lo largo de su historia ha reconocido como incumbencia suya, hasta recono. cerla como la fundamental, el dar razón de sí misma ante alguna otra instancia o ante sí misma. El vulgo extrafilosófico, de acuerdo en esto con ella misma, suele preguntar para qué sirve la filosofía, cuando perentoriamente no concluye que no sirve para nada, o que no tiene justificación. La filosofía ha solido responder, y justificarse también ante sí misma, aduciendo una doble o triple utilidad: dar satisfacción al afán de ver y saber connatural al hombre, y enseñar a éste a comportarse o conducirse correctamente o bien en el pensamiento y conocimiento y en la vida entera. El afán de ver y saber y la satisfacción de él se conceptúan tradicionalmente de antiutilitarios o inutilitarios, por contraposición a toda utilidad - práctica. Pero si toda utilidad práctica radicase en dar satisfacción a alguna necesidad o afán, el dar satisfacción al afán de ver y saber no dejaría de ser una utilidad — teórica. En todo caso, el enseñar a conducirse bien en la vida entera se conceptúa tradicionalmente de utilidad práctica, incluso la suma, y por ello como la justificación también suma, o más radical, de la filosofía. Tal justificación de la filosofía sería, pues, la ética, tanto cuando se concibe la metafísica como una fundamentación, o razón teórica, de la ética, cuanto cuando se concibe la ética como la fundamentación, o razón teórica, de la metafísica, y la moral como la justificación, o razón práctica, de lo metafísico, del objeto de la metafísica.

Pues tradicionalmente se ha venido pensando que el enseñar al hombre a conducirse bien en la vida entera era la incumbencia peculiar de la ética. $Y$ ello porque también tradicionalmente se ha venido pensando que el conducirse bien en la vida consistía, desde luego, en la moralidad de la conducta, y conducía, como fin y por fin, a la felicidad, si no en este mundo y esta vida, en otros; y que la ética es la ciencia de la moralidad y, de consuno, de la felicidad. Las éticas antieudemonistas o aneudemonistas son excepciones de re. acción crítica —no sin justificación.

Porque la concepción de la identificación, antes o después, de la moralidad y la felicidad es tan problemática, que no es más que un postulado, él mismo problemático para la razón pura, por mucho que sea postulado de la razón práctica. Nuestra virtud no tendría sentido si no se encaminara a la

1 Lección de introducción al segundo semestre del curso. Colegida de las dadas, con variantes, en años sucesivos. 
identificación con la felicidad en el más allá nouménico - pero jasintótica. mente!

Pudiera, pues, ser, en primer término, que la moralidad y la felicidad fuesen cosas tan divergentes como para no coincidir realmente jamás; y en tal supuesto, si la ética es la ciencia de la moralidad, y la felicidad el fin úl. timo del hombre, y alguna ciencia capaz de enseñar, ya no a ser moral, sino a llegar a ser feliz, tal ciencia no sería la ética, sino una ciencia de la felicidad, independientes, felicidad y ciencia de ella, de la moralidad y de la ética, en suma, una eudemonología autónoma - de la ética y, en general, como disciplina, filosófica o no.

Históricamente, entrañada en la ética, confundida con la ética, pero tendiendo a independizarse de ella, y también entrañada en otras disciplinas, extrafilosóficas, o confundida con ellas, existe tal disciplina, la eudemonología. En las éticas eudemonistas está entrañada o con la ética confundida. En la literatura del arte de amar está entrañada o con ella confundida, como en una de sus especies o partes el género o el todo. $\mathrm{Y}$ en cuanto esto se advierte, se advierte también lo rico de la literatura eudemonológica, de las fuentes de conocimiento de la eudemonología, que parecen ser nada menos que las de la felicidad misma o del conseguirla y lograrla.

Pero ¿y si la felicidad no fuese el fin último del hombre? ¿si no pudiera decirse "el arte de vivir $o$ de ser feliz"?... Una concepción como la nietzscheana del "no contentamiento, sino más poder", plantea el problema, deba ser la solución afirmativa o denegativa. Quizá toda concepción semejante se funde en un concepto estrecho de la felicidad; quizá sea reacción, contra las mezquindades que han hecho y hacen la felicidad del vulgo de todos los lugares y tiempos, de las almas o espíritus nobles, de ambiciones más esforzadas o aspiraciones más elevadas; pero la satisfacción de éstas, la del mero tenerlas o perseguir su satisfacción real o cabal, ¿no será la felicidad de tales almas o es. píritus? Cualquiera que sea la respuesta, será respuesta a un problema, que no excusa del planteo de éste, sino que lo presupone. Sólo que todavía pu. diera haber más.

La única eudemonología de un filósofo constituida y presentada por separado, son los "Aforismos sobre la sabiduría en la vida" contenidos en los Parerga y paralipómena de Schopenhauer a su sistema. La introducción a ellos dice: "Tomo aquí el concepto de sabiduría en la vida exclusivamente en sentido inmanente, a saber, en el del arte de pasar la vida lo más grata y felizmente posible, la enseñanza del cual pudiera llamarse también eudemono. logía: sería, según esto, la guía para llevar una existencia feliz. Ésta podría a su vez definirse, si se quiere, como aquella que, contemplada de un modo puramente objetivo, o más bien (pues que aquí se trata de un juicio subjetivo), reflexionando fría y maduramente, sería resueltamente preferible al no ser. De este concepto de ella se sigue que nos apegaríamos a ella por ella misma y 
no meramente por miedo a la muerte; y de aquí a su vez que quisiéramos verla de una duración sin fin. Si la vida humana responde al concepto de una existencia semejante, o si puede, simplemente, responder a ella, es una cuestión que niega, como es sabido, mi filosofía; mientras que la eudemonología presupone la afirmación de ella. Ésta descansa, en efecto, justo en el error innato cuya censura abre el capítulo 49 del segundo tomo de mi obra principal. Para poder, con todo, elaborar una, he tenido, por ende, que prescindir por entero de la superior posición metafísico-ética a que conduce mi verdadera filosofía. Por consiguiente, descansa toda la exposición que se va a hacer aquí en una acomodación, por así decirlo; a saber, en cuanto que se queda en la posición habitual, empírica, y se afirma en su error. Según esto, sólo un valor condicional puede ser el suyo, pues que la misma palabra eudemonología es sólo un eufemismo." Estas palabras dan una expresión un tanto balbuciente a una idea contradictoria, por no ser suficientemente clara y distinta, de la divergencia entre la eudemonología y la sabiduria en la vida, entre la vida feliz y una vida preferible al no ser -aunque no fuese feliz; divergencia in. cluso por razones metafísicas...

Cuando la misma ética eudemonista se resiste a ser ética hedonista, a poner en el placer la felicidad, si entiende por placer exclusivamente el sensi. ble y en este sentido el hedonismo, puede no hacer más que poner la felicidad en placeres no sensibles simplemente no llamados placeres; pero si entiende también éstos por placer y en este sentido el hedonismo, no puede hacer más que poner la felicidad en algo que se parecería mucho a una vida infeliz pero que, a pesar de todo, "valdría la pena". La expresión vernácula "vale la pena" algo, significa corrientemente que algo que no consiste en pena vale por ello la de conseguirlo; pero puede ahondársela hasta darle la significación de que algo consistente en pena, valdría ésta, a pesar de ella, como podría ser, una vida sin felicidad.

Si la solución del problema fuese, pues, no ser la felicidad el fin último del hombre, no poder decirse "el arte de vivir o de ser feliz", habria que distinguir, no ya de la ética la eudemonología, sino de toda ética eudemonista y de toda eudemonología propia y simplemente tal, una ciencia o arte de vivir, para la que no hay nombre griego, que yo sepa, lo que me parece debido a lo insólito de la separación misma de la felicidad y una vida que sin ella "valga la pena".

Ciencia o arte de vivir o de ser feliz, identificativo o disyuntivo el segundo "o", sus dominios parecen cardinalmente los dos que responden a la vieja y sabia concepción de la vida humana a que da autorizada y castiza expresión castellana la conocida estrofa del Arcipreste:

Como dize Aristótiles, cosa es verdadera:

El mundo por dos cosas trabaja: la primera, 
Por aver mantenençia; la otra cosa era Por aver juntamiento con fenbra plazentera.

Ciencia o arte de amar y de trabajar, sea para ser feliz, sea para vivir sin ser feliz, pero de suerte que valga la pena. Dos dominios de la vida privada, aunque el de la vida profesional cabalgue sobre la frontera con la vida pública. Lo que hace reparar en que la eudemonología, ética o autónoma, parece disciplina de la vida privada e íntima más que de la pública, como si la felicidad fuese asunto o negocio íntimo o privado y no interés público. Mas lo que parece pasar, es haber como una evolución histórica, si no continua, alternativa, en el sentido de la absorción de lo privado por lo público, hasta la de la felicidad, como exhibiría ya la concapción del Estado benefactor, no se diga la del Estado totalitario. Sin embargo, al punto se atisba que el arte de ser feliz o de vivir ha de ser últimamente un arte de la intimidad también última, quizá de justificarse últimamente ante sí mismo —el valer de la pena.

Ciencia o arte de tal intimidad y de la vida privada y pública, del trabajar y del amar, del ser feliz o del vivir, diferente de la eudemonología o consistente en ésta, autónoma o confundida con la ética o entrañada en ella, ha tenido y debe tener ciertos fundamentos.

Desde los primeros filósofos se concibió lo que era ya metafísica, aunque asi no llamado hasta mucho después, como el fundamento de la ética. Así sería ya en la obra de Heráclito, si estaba dividida o era divisible en una introduc. ción lógico-gnoseológica y sendas partes cosmológica, antropológica y éticoreligiosa. Pero si así fuese, la metafísica de la naturaleza no sería el fundamento directo de la ética, sino a través de la antropología. Situación pareja, en el sistema culminante de la historia entera de la filosofía desde los orígenes de ésta hasta el primer gran sistema de la filosofía moderna. La filosofía primera de Aristóteles puede concebirse como el fundamento de todo el sistema. Pero esta relación sería entre la metafísica y la ética peculiarmente complicada. La metafísica se inicia con una teoría de los grados del saber, culminantes en el de la ciencia de los primeros principios - de lo ente en cuanto tal, según se precisa sólo más adelante-, y de tal forma naturales al hombre, que la teoría es en el fondo una teoría de la naturaleza humana, un rudimento de antropología; y ya tal teoría preludia, al exponer las características de la ciencia de los primeros principios y entre ellas la de su divinidad, el gran tema en que la metafísica toda culmina: la teología del dios teólogo o puro pensa. dor de sí mismo, en quien la teoría, lo más placentero y lo mejor que existe, es la felicidad, y de cuya teología o teoría y felicidad participa el teólogo humano, el filósofo, en las raras ocasiones de su filosofar en plenitud o hacer tal teología plenamente. De la ética es el centro la teoría de las virtudes intelectuales, de las que es la intelección de los primeros principios la culminante, y es la cumbre la teoría de la felicidad, fin último del hombre, que la pone en 
aquella teologia. Mas la ética es tanto, si no más, fundamentalmente, antropología. La areté, lo que se traduce por virtud, es más propiamente que virtud moral en el sentido corriente actual, una excelencia de una naturaleza o de un sujeto: de un sentido mucho más cercano, que al de la virtud del virtuoso moralmente, a la virtuosidad artística o al de virtus -con que tradujeron areté los latinos - en pasajes como éste en que pondera Séneca la de Mucio Scevola: quanto acrior sit ad occupanda pericula virtus quam crudelitas ad irroganda, en que la significación del término es valor heroico, heroísmo; o al de virtí en los versos de Petrarca a Italia - con la cita de los cuales cierra Maquiavelo el Principe - que muestran el término sinónimo del de valor:

Virtù contra furore

Prenderà l'arme; e fia 'l combatter corto;

Che l'antico valore

Nell'italici cor non è ancor morto.

Si no fuese así, no podría ser el centro de la ética la teoría de las virtudes intelectuales; y menos aún podría poner Aristóteles por ejemplo de virtud la del buen caballo de batalla, que en vez de amedrentarse con las hostilidades y retroceder ante ellas, con ellas se enardece y arremete contra el enemigo. El ejemplo bastaría para enseñar que por la virtud o excelencia natural de bravura del caballo hay que entender la del hombre, y no por la virtud moral de valentía del hombre la virtud del caballo. Ahora bien, la teoría de las exce. lencias de la naturaleza humana, las morales, consistentes en sendos términos medios entre sendas parejas de extremos, y las intelectuales, es una teoría de la naturaleza humana misma, una antropología, por mucho que, de otra parte, vea al hombre como veía al hombre griego un hombre griego como era Aristóteles, relatividad histórica de toda filosofía, como de toda literatura y quizá de toda ciencia.

En el curso de la historia fueron modificándose las relaciones entre metafísica, antropología, ética - y eudemonismo o eudemonología. Para tomar otro caso, innovador y también cimero: en Kant, es la constitución estéticocategorial-ideadora del sujeto de la ciencia matemática y física y la seudo. ciencia metafísica el fundamento al par de la necesidad y de la imposibilidad de esta última; y si no es la ética el fundamento teórico de la ciencia metafísica, es la constitución moral del sujeto el fundamento práctico quizá de la realidad misma del mundo objeto de la seudociencia metafísica tradicional, del que es singular punto la identificación asintótica de la virtud y la felicidad; o en suma, es una peculiar antropología el fundamento de la crítica de la metafísica y de la ética - y eudemonología, pues, en contra de las afir. maciones en contra, incluso del propio Kant, hasta un rudimento de ella hay, por poco prometedor que sea, en tan singular punto. $\mathrm{Y}$ para poner, por fin, el 
caso históricamente terminal hoy, en nuestros días ha venido a ser la antropología la disciplina filosófica fundamental, desde la metafísica hasta la ética, como empezó decisivamente con Scheler, aunque acaso más para su metafísica final del impulso y el espíritu que para su anterior ética de los valores, y como ha acabado quizá definitivamente en $E l$ ser y el tiempo, intento, significativamente frustráneo, de fundamentar en la analítica existenciaria que, aunque su autor no quiere que sea una antropología, puede conceptuarla de tal quien no es su autor -la ontología, que contiene un intento de fundamentar la moral en la constitución existenciaria del sujeto. $O$ en conclusión: que la antropología parece crecientemente $e l$ fundamento de la ética, de la eudemonología - y del posible arte de vivir aneudemonológico.

Si estas disciplinas han realmente menester de una fundamentación antropológica, la antropología ha menester, a la inversa, de una justificación por su utilidad para ellas. La antropología no es menos menesterosa de justificación que -nada. Pues, ¿qué justificación hallarle más apropiada que la que se presenta como natural y patente vocación suya: servir el conocimiento de si mismo al hombre para conducir su vida — moralmente, hacia la felicidad o de suerte que le valga la pena vivirla?__ Quizá sea posible dar al "y" del título "Antropología y eudemonología" una significación lógica más rigurosa, si la eudemonología fuese tal verificación de la antropología que permitiera articularlas en forma de teoría deductiva: si, y sólo si, el hombre es tal o cual, entonces es feliz o infeliz, o vive una vida que vale la pena o no.

Pero ¿qué antropología? -ya que la ciencia del hombre viene desarrollán. dose con acelerada proliferación, y hay una antropología filosófica y una antropología científica, y en ésta una antropología física y una antropología cultural y social, y además una psicología, psicopatología, psiquiatría, psicoanálisis e higiene mental entre las cuales y aquéllas no hay solución de continuidad - y lo que de antropología hay en la literatura, o de ésta puede sacarse para la antropología, que no es poco, y no sólo en los tratados de amor, desde el poético de Ovidio al prosaico de Stendhal o el monomaniático de Michelet, sino hasta en la poesía más pura. Claro que todo lo aprovechable como fun. damento de ética, eudemonología, arte de vivir, debe aprovecharse. Pero de nuestro interés son únicamente, por ser lo único de nuestra competencia, la antropología filosófica, por un lado, y, por otro, la eudemonología o el arte de vivir. Para nosotros se trata, por lo tanto, exclusiva y precisamente, de la antropología filosófica como fundamento de la eudemonología o arte de vivir.

La antropologia filosófica está tan dividida en antropologías filosóficas como la filosofía en general en filosofías. Pero quizá de toda antropología filosófica puedan sacarse doctrinas aprovechables por una eudemonología o arte de vivir para una efectiva vida feliz o que valga la pena. En la primera mitad del curso de antropología filosófica cuya segunda mitad va a ser la 
eudemonología o arte de vivir que prologa esta lección, se ha expuesto una concepción del hombre que puede resumirse como paso a hacer.

El hombre está bien definido tradicionalmente por la palabra -razón, por la expresión verbal o del pensamiento. La razón (facultad) es, en un primer sentido, el razonar o raciocinar, el pensamiento discursivo. Éste es un ir dando razón (acto o pensamiento) de todo que está dominado por ciertos conceptos, las categorías. La razón es, en un segundo sentido, pensamiento categorial. Entre las categorías se destacan como sumas, o radicales, las negativas de inexistencia de todo, o de nada, y de infinitud. La razón es, en un tercero y un cuarto sentidos, pensamiento negativo y pensamiento de lo infinito.

Si la razón va dando razón de todo, llegará a darla de sí misma, o sobre todo, o bajo todo, de sus categorías, particularmente de las negativas de nada e infinitud. Pero se encuentra con que de estas categorías no puede darse razón por los objetos del pensamiento en general o por los objetos empíricos del pensamiento, sino únicamente por los sujetos que piensan tales categorías -o con ellas, no en ellas-, los sujetos de ella misma, de la razón, es decir, por aquello de tales sujetos que no es ella misma, por lo irracional de tales sujetos. Encuentra, en efecto, que puede darse razón del poder concebir como inexistente cualquier existente, hasta lo existente, que es el concebir la nada, y del concebir como infinitud por excelencia la del infinito Bien, por el amor o el odio de sus sujetos, de los sujetos racionales, a las entidades y existencias de los entes vividas como bienes o como males, o sea, por la constitución moral de tales sujetos. Pero también se encuentra con que de esta constitución moral ya no puede dar razón, y en esta impotencia reconoce sus propios límites, y en este reconocimiento la última sabiduría acerca de sí misma. Porque no sería dar razón de la constitución moral de sus sujetos reconocer una corre. lación entre ella y la finitud. El ente finito no puede serlo todo, tiene que elegir, tienen que elegirle, lo que es un correlato de la distinción entre bueno y malo del que conjuntamente con ésta ya no encuentra la razón razón que dar. En otros términos: la constitución del hombre, o la naturaleza humana, es una constitución o naturaleza racional oriunda de una constitución o naturaleza moral —oriunda no sabe aquélla, con el saber propio de ella, de dónde. En términos de la filosofía clásica de la que se reconoce más cerca lo resumido: la razón pura puede dar razón de sí por la razón práctica, que da razón, pero práctica, de la pura y de sí; pero la razón pura no puede dar razón de la práctica. El dar razón puede ser un dar una razón pura, o fundamentación, como la de un teorema matemático, o un dar razón prácticamente, o justificación por una acción, no por el aducir ésta la razón pura, sino por la acción misma, como la justificación del pecador - todo hombre, tras el pecado originalpor la Redención o la muerte misma del Verbo encarnado. En términos de filosofias de nuestros días: el hombre es el ente racional y moral del misterio 
de su propio puesto en el cosmos, del origen y sentido de la aparición de un ente racional y moral en la Naturaleza, o de la verdad de su propia naturaleza.

Mas aunque la razón no pueda dar razón de la constitución moral por la que se da razón de sí misma, con tal constitución podría dar razón, además de dársela de sí misma, de una eudemonología o arte de vivir. La antropología sería la teórica fundamentación de la cudemonología, y ésta en cuanto arte la justificación práctica de la antropología y de sí misma. Lo radical de la constitución moral de los sujetos de la razón está en un desnivel dinámico, de un complejo dinamismo, no sólo zozobrante (zozobra viene de sub-supra, de submersión o sumergirse y emergencia o sobrenadar), sino a la vez oscilante, o doblemente desequilibrado; onto-axio-lógico, o de finitud de posibilidades e incertidumbre entre relativos bienes y males reales y un ideal y absoluto Bien. De esta constitución ęno podría inferirse una eudemonología o arte de vivir de la que pudiera conceptuarse aforismo capital éste?: "Procurar en todo lo más y contentarse en todo con lo procurado efectivamente. Sin lo primero, no habría nunca más que vida mediocre. Sin lo segundo, no hay más que vida infeliz."

El término de contento tiene una semántica y una historia instructivas. Designa no sólo satisfacción y felicidad, sino también, y primitiva, etimológicamente, contención, continencia, y tender y contender, tensión y contienda, esfuerzo. Esta mínima semántica basta siquiera para insinuar que un pugnar hasta un límite es hacer bastante, dar abasto o es abastanza; pero que para arribar a ésta por una limitación, es indispensable la pugna cuyo ha de ser el límite. Así lo vieron o atisbaron ya los antiguos, primer gran repucsto de arte de vivir. Virtutem ad beate vivendum se ipsa esse contentam, cs cl título de la última de las Cuestiones Tusculanas. Por su lado, el contrario término de des-contento hace vislumbrar relaciones profundas con los de desnivel y, más aún, desequilibrio. $Y$ el principio enunciado pudiera entrañar una síntesis de principios de vida, de la antigua y de la moderna: a las éticas de la Antigüedad, desde luego a las de la apatia o insensibilidad, ataraxia o imper. turbabilidad, pero también a la del término medio, éticas de una cultura para la que la hybris o demasía irritaba los celos y acarreaba la venganza de los dioses, les faltó el "heroico furor" del espíritu fáustico de los modernos, cuya ilimitación es desmesura que algo tiene que aprender de la mesura o modera. ción de los antiguos.

¿Cómo se detallaría tal principio en aplicación a los temas anteriormente reconocidos como los capitales de un arte de vivir, el trabajar y el amar? La respuesta detallada a esta pregunta será el resto del curso.

En todo caso, la eudemonología que puede y debe fundarse en la resumida constitución del hombre no puede ser solamente eudemonología. La palabra eudemonología tiene por componente la palabra eudemonio, que quería decir 
etimológicamente lo que se traduce bien por buen genio. $Y$ no es extraño a ni para la experiencia humana que el tener un buen genio, y más que uno ajeno y protector el propio, dé por resultado la eudemonía o la felicidad. Pero una eudemonología, ciencia o arte del buen genio y de la buena vida, no puede considerar con preferencia exclusiva éstos, aunque los considere con predilección y de ellos solos tome el nombre; debe considerar con igual atención, por poco dilectos que puedan serle, los respectivos contrarios, el mal genio y la mala vida, el cacodemonio y la cacodemonía, o debe ser, tanto como eudemonología, cacodemonología. Razón tan radical como decisiva: que la constitución del hombre en que puede y debe fundarse es una constitución en que el mal tiene tanta realidad e importancia, por lo menos, como el bien, o que sin el mal no se comprende, en absoluto. Mas resulta, y bien sorprendentemente, por cierto, al reparar en ello, que si la maldad del hombre es un lugar común, que han tomado en serio, para desarrollarlo debidamente y sacar las forzosas consecuencias, tradicionalmente las religiones, los moralistas, los literatos y últimamente también la psicopatología y la psiquiatría, no lo han tomado igualmente, a juzgar por los desarrollos que - no le han dado y las consecuencias que no han sacado, los filósofos. La sorpresa se desvanece cuando se repara más: en que a los mayores y a los más de los filósofos les ha interesado demasiado exclusivamente la superioridad del hombre, la razón, lo divino del hombre, el Bien -por interesarles, con preferencia en rigor no menos natural en ellos, como pensadores, sino más natural en ellos, como motivación esencial y característica de su pensamiento, su propia superioridad -en lo que está su soberbia-, su propia identificación por medio de la razón con lo Divino y con el Bien. Que es por lo que son las obras absolutamente maestras de la filosofía universal, desde la Metafísica de Aristóteles hasta la Lógica de Hegel, teología, o crítica de ésta, pero no demonologia - hasta un extremo como el de declarar puras apariencias falaces, si no meros flatus vocis, los conceptos de bueno y malo, a pesar de su entidad de yerros humanos. Es notable que el término demonio, etimológicamente neutral como para poder y necesitar componerse con eu y con cacós, acabara por asumir el sentido de este último componente expeliendo el del contrario: el demonio vino a ser el malo, exclusivamente, y hasta por excelencia, si ésta cabe, aunque sea como paradoja, en la maldad. Todo esto significa que una antropología filosófica cabal tiene que rectificar a los más grandes filósofos en ser tanto demonología cuanto teología, y por eso, según se adelantó, una eudemonología fundada en ella, otro tanto cacodemonología.

Este nombre podría resultar tan impropio como el de eudemonología, si la capital cuestión de las relaciones entre la bondad o maldad moral, la feli. cidad o infelicidad y la vida que valga la pena o no, o la vida buena o mala en un sentido distinto a la vez del ético y del eu- y caco-demonológico, resultara resuelta en este último sentido. Esta cuestión no parece soluble antes de en. 
trar en la disciplina, ni siquiera con más o menos pasos dentro de ella, sino únicamente por medio de ella entera. Por lo tanto, hay que emprender la obra de constituir la disciplina que andamos buscando - como Aristóteles la ciencia de la filosofía primera-, teniendo presente, como hipótesis de trabajo, la posibilidad de la necesidad de distinguir finalmente en el sentido repetido. Si la hipótesis se verificara, la obra emprendida resultaría, no una eudemonología, con su cacodemonología, sino un arte de vivir aneudemonológico, y acacodemonológico - y perdón por tantas palabras tan cacofónicas sobre pedantescas-, para el que habría que buscar un nombre más propio y más estético. El utilizar la distinción producida entre el sentido final. mente predominante de eudemonía, felicidad, y el correlativo de cacodemonía, infelicidad, y el sentido etimológico de eudemonio y cacodemonio, o demonio a secas, buen o mal genio, para entender por eudemonología y cacodemonología la ciencia o el arte no de la vida feliz o infeliz, sino de la buena o mala vida en el sentido de la vida que valga la pena o no, aunque no dejase sin nombre a una disciplina entonces no existente, quizá en vez de distinguir confundiese, da la tradición semántica del término eudemonología.

Quizá por otras relaciones entre la anterior cuestión y otra, que aún queda como previa, y bien crítica, en todos sentidos, es la única manera de resolver ésta la misma que se acaba de indicar como única para resolver la anterior. Esta última cuestión es la de la posibilidad misma de una ciencia o arte de vivir, eudemonológica o no. Y en el planteo de la cuestión hay que hacer una distinción capital, desdoblándola. ¿Será posible una ciencia teórica, un puro conocimiento científico, de la vida feliz, de la felicidad, o de una vida que valga la pena? $\mathrm{Y}$ ¿será posible una ciencia práctica, o arte en este sentido, de vivir feliz o de llevar una vida que valga la pena, es decir, un conocimiento, científico, utilizable efectivamente para llevar tal vida o vivir feliz?

La vida feliz, la vida que valga la pena, la vida _-humana, no biológicaen general, podría no ser objeto de ningún conocimiento propiamente cien. tífico, si no de nada que fuese propiamente conocimiento. Si ciencia es un cuerpo de proposiciones articulables en forma de teoria deductiva — si y sólo si tales postulados, entonces tales teoremas, no contradictorios entre sí o verificables empíricamente, todo ello por igual para todo sujeto capaz de comprender la teoría y de la verificación empírica de ella, eno pasa que, aunque sobre la vida feliz, la vida que vale la pena, la vida en general se han enunciado y se enuncien aún proposiciones innúmeras, éstas no son articulables en forma de teoría deductiva, son contradictorias, no son verificables empíricamente, con una efectiva vida feliz o que valga la pena, por igual, no ya para todo ser humano, pero ni siquiera para todo filósofo o todo eudemonólogo? Piénsese en lo que el conocimiento de la vida y la valoración de ésta dependen de las diferencias de raza o pueblo, de época histórica, de clase, de profesión, de sexo, de edad, de personalidad individual. Por ejemplo, ¿podrá hacer un 
viejo profesor una eudemonología, no ya aprovechable, pero ni siquiera comprensible, para jóvenes alumnas?

Pero aun teniendo un conocimiento científico de la vida, y de su valor o valores, de la felicidad, podría no ser utilizable efectivamente para llevar vida alguna, si, en contra de un tradicional y corriente, pero quizá sólo prejuicio intelectualista, el conocimiento, ni el científico, ni el incientífico, no sirviese para la acción, sino que ésta fuese exclusivamente efecto de causas irracionales y hasta incognoscibles. Aunque hubiese un cuerpo de proposiciones que dijese: "si y sólo si eres u obras así, entonces eres o serás feliz, o llevas o llevarás una vida que valga la pena", y todos los humanos verificasen en la vida de unos y la de otros que únicamente los que eran $\mathbf{u}$ obraban así eran felices o llevaban una vida que valía la pena para ellos, si no para todos, tno podría ser que el conocimiento de todo esto no fuese potente para hacer ser $u$ obrar así, porque así o de otra manera se fuese o se obrase únicamente por causas incognoscibles o incontrolables? Ya la ética ha evolucionado históricamente del concebirse predominantemente como disciplina práctica, como arte del vivir moral, a concebirse predominantemente como pura disciplina teórica, cual si hubiese reconocido que si la vida moral es posible y efectivo objeto de ciencia teórica, esta ciencia no sería utilizable para vivir moralmente, lo que sería efecto de otras causas. La autonomía de la razón práctica — respecto de la pura - es su irracionalidad en el sentido de ésta. Como la moralidad, felicidad o infelicidad, buena o mala vida no dependerían, si no exclusiva, principal, radicalmente, del conocimiento o la ignorancia, así que sería forzoso en mayor o menor medida el obrar a ciegas, la incertidumbre y el escepticismo en la materia más vital de todas; la necesidad de fiarse en ella al instinto, a la naturaleza, que con los hechos muestra y demuestra no ser siempre materna.

"Nadie escarmienta en cabeza ajena" -quizá ni en la propia. El no escarmentar nadie en cabeza ajena pudiera significar no más que la imposibilidad de la "intersubjetividad" del conocimiento científico en materia de vida. Pero el no escarmentar ni en la propia cabeza pudiera significar más bien la imposibilidad de que el conocimiento, ni científico ni incientífico, dirija la vida, al menos en proporción suficiente para ser feliz o vivir valiendo la pena. Quizá sea imposible aprender a vivir, no ya en libros o lecciones, ni en la experiencia ajena, pero ni siquiera en la propia: pues aun reconociendo que la vida enseña, ¿si se pasase la vida en aprender a vivirla -para morirla? Llegaría a faltar por el conocimiento de la vida el interés motor de todo conocimiento, justo en el punto único en que sería posible poseerlo efectivamente. Pero aun no extremando tanto las cosas, si fuese cierto que por lo menos en cabeza ajena no se escarmienta, y condición sine qua non de la cien. cia la validez intersubjetiva, la eudemonología fundada en la propia experiencia exclusivamente no sería ciencia alguna.

Si la una de ambas posibilidades, o más bien imposibilidades, anteriores, 
equivaliese en el fondo a la imposibilidad de una antropología científica, lato sensu, es decir, abarcando la filosófica, quizá esta imposibilidad de la antropología fuese menos razón para rechazar sin más la del conocimiento científico de la vida, que la imposibilidad de este conocimiento razón para revisar la posibilidad de la antropología científica o la índole científica de la antropo. logía -con las ciencias humanas en general, por comparación y a diferencia de las exactas y naturales, según he hecho por mi parte en otros lugares como no voy a repetir en éste.

Acabo de decir "revisar" muy intencionalmente. Pienso, en efecto, que la resolución de semejantes cuestiones no puede ser previa a la constitución de las disciplinas que las plantean. Para poner el más egregio de los ejemplos: la crítica de la metafísica, la teoría del conocimiento no puede preceder a la metafísica misma. Primero hay que hacer, hubo que hacer metafísica - para poder criticarla. No se puede aprender a nadar antes de echarse al agua. En esto me parece que tiene razón Hegel contra Kant. Este no hubiera podido componer la Crítica de la razón pura si no estuviese alli, de hecho, en la historia, la metafísica - como la matemática o la ciencia exacta de la naturaleza. En revisar las tres comparativamente consistió la crítica kantiana. Análogamente, con todas las disciplinas y la discriminación de su indole científica o no tal. Primero, pues, hacer antropología, teoría de la vida, y si se hace alguna, entonces revisarla críticamente bajo el punto de vista epistemológico, gnoseológico.

Pero no puede decirse lo mismo de la ciencia práctica o arte de vivir. Decir: "primero vivir y luego utilizar el conocimiento para vivir", es una contradicción, un contrasentido. La teoría de la acción no puede más que seguir a ésta. La crítica de la teoría o del arte no puede más que seguir a éstos. Pero el arte mismo, que es la teoría para la acción, no puede seguir a ésta; no puede más que precederla, para poder guiarla; o no sería arte, o con todo rigor, no existiría.

Lo que se puede y debe hacer es, en conclusión, lo siguiente:

tratar de ir labrando una eudemonología - con fundamentos y bajo puntos de vista como los expuestos- o de ir apropiándose lo que de eudemonología haya labrado o vaya labrándose;

ir revisando epistemológica o gnoseológicamente la que se vaya labrando o apropiando;

tratar de utilizar la que se vaya labrando o apropiando para vivir;

y lógrese la utilización o resulte frustránea, tratar de averiguar las razones del éxito o del fracaso.

José GAOS 